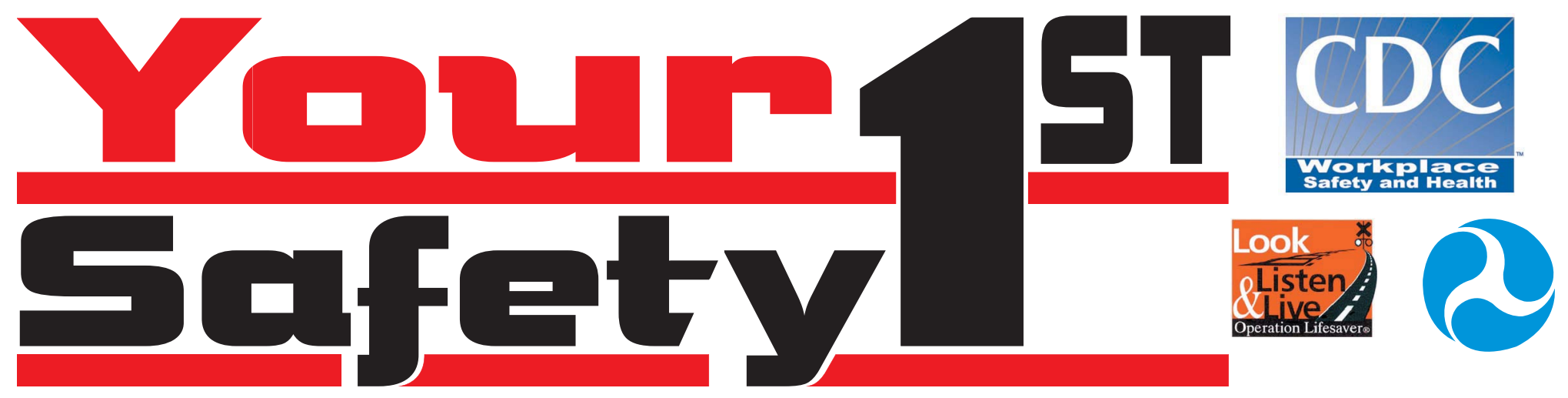

Railroad Crossing Safety for Emergency Responders

JUNE 2003

\title{
Death in the Line of Duty
}

In March of 2002, a 48-year-old volunteer fire fighter in Kentucky, driving a tanker truck, received fatal injuries after being struck by a freight train and thrown from his vehicle as he attempted to cross a private, ungated railroad crossing. The fire fighter was returning the apparatus to the station following a training exercise.

Two years earlier, a 31-year-old career fire fighter in North Carolina died after the ladder truck he was driving collided with a train at a railroad crossing with two sets of tracks. He was returning to the station after a false alarm. The gates at the crossing were down and warning lights activated. The northbound train moved slowly forward, then stopped after clearing the crossing to wait for permission from the dispatcher to proceed. A tanker car obstructed the fire fighter's view of an approaching southbound train. He drove around the first lowered gate, over the tracks and into the path of the second train. The force of the impact ejected the fire fighter from his vehicle, resulting in his death.
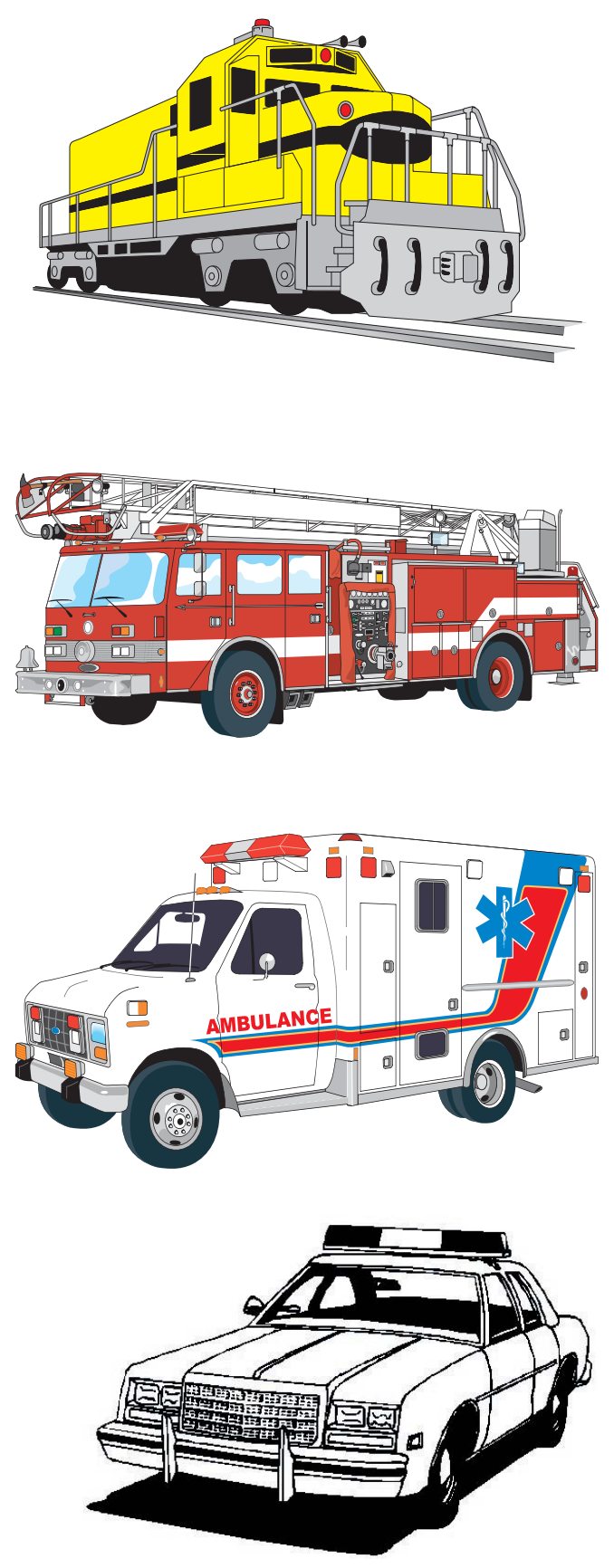


\section{DRIVING TIPS}

LOOK

Plan your routes to avoid highway-rail grade crossings. Otherwise, use crossings with active warnings and clear sightlines down railroad tracks in both directions.

LOOK both ways before crossing. Trains can come from either direction.

Come to a complete stop at all crossings with passive warning devices (no gates or flashing lights). Use caution and be prepared to STOP at all crossings with active warning devices (flashing lights, gates). Per National Fire Protection Association (NFPA) Standard 1500 Sec. 4-2.8.

When stopped, be sure your front or rear bumper clears the nearest track by at least 15 feet.

LSTEN Before crossing, roll down windows, turn off siren and radio, and listen for train horn.

\section{LIVE}

Always ....heed flashing lights, closing gates and stop signs.

Wait.........until safely through the crossing before shifting gears or passing.

Never ......back up or stop on tracks. If gate comes down on the vehicle, keep going through the crossing.
DO NOT STOP ON TRACKS

\section{CROSSING INFORMATION}

Most railroad crossings have information that identifies their location, the railroad that uses that track, and an emergency 800 contact number. This information needs to be used when:

- Your vehicle is caught on the crossing and/or in some way blocks the track or

- The incident you are responding to involves a vehicle or pedestrian on or near a crossing

Locate the U.S. DOT Inventory Crossing Number (six numbers and a letter) that identifies your location, and the toll-free emergency contact number. These numbers are usually found on the crossbuck post or the post where the crossing gates are secured. Call the phone number provided and report your emergency.

\section{$988988 \mathrm{E}$}

Example of U.S. DOT Inventory Crossing Number. This number can usually be found on the sign with contact information
REPORT EMERGENCY

TO 1-XXX-XXX-XXXX

CROSSING \# XXX-XXXX

ON STREET NAME ROAD

Recommended Emergency

Notification Format

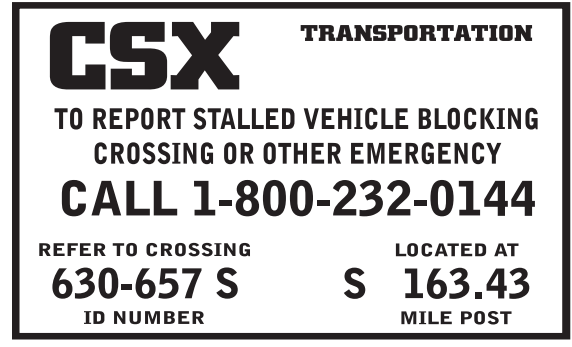

Example of posted sign 


\section{SIGNS \& WARNING DEVIGES}

\section{ADVANCE WARNING SIGN}

- Posted on side of road to denote railroad tracks ahead.

PAVEMENT MARKING

- Denotes railroad crossing ahead.

\section{CROSSBUCK}

- Fire fighter apparatus must come to a complete stop per NFPA standards.
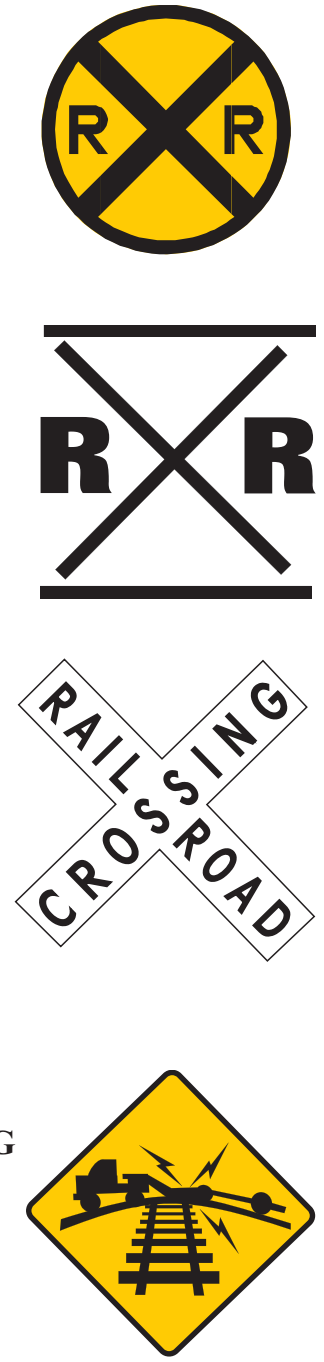

HUMPED - HIGH PROFILE CROSSING - Low clearance vehicles should not attempt to cross. You may get hung up on tracks.
YourSafety

NIOSH, the National Institute for Occupational Safety and Health, the Federal Railroad Administration, and Operation Lifesaver, Inc. remind you to be pro-activeyour safety first so you can get to the call

\section{IF A TRAIN COMES}

If your vehicle becomes hung up or stalls on the crossing, get everyone out and keep a safe distance from the tracks. If time permits before exiting, turn on the vehicle's emergency lighting system (strobe light, flashers). If you hear or see a train approaching, move everyone at the crossing away from the tracks in the direction of the oncoming train. When a locomotive strikes a vehicle, it pushes it forward. By heading in the direction of the oncoming locomotive you'll be moving away from any debris resulting from the impact.

\section{FOR MORE INFORMATIONE}

\section{NIOSH}

[www.cdc.gov/niosh/firehome.html]..... (800) 356-4674

- A train is coming-DO NOT cross!

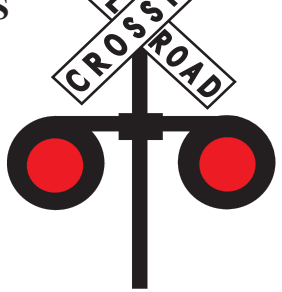

\section{Department of Transportation}

Federal Railroad Administration

[www.fra.dot.gov].

Federal Highway Administration

[www.fhwa.dot.gov]

(202) 366-1153

Federal Transit Administration

[www.fta.dot.gov]..... (202) 366-4043

National Highway Traffic Safety Administration

[www.nhtsa.dot.gov].... (202) 366-9550

Operation Lifesaver, Inc.

[www.oli.org]... (800) 537-6224 


\section{DID YOU KNOW?}

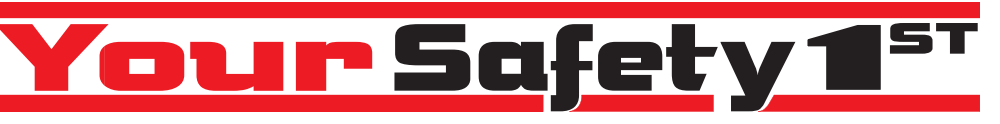

\section{RAILROAD CROSSING SAFETY FOR EMERGENCY RESPONDERS}

Approximately every 2 hours, a train hits a person or vehicle.

Nearly half of all vehicle-train collisions occur at crossings with functioning, active warning devices.

Trains cannot stop quickly or swerve to avoid collisions - an average train going $55 \mathrm{mph}$ takes more than a mile to stop!

Optical Illusion - Trains are much closer and moving faster than they appear to be.

Average freight trains weigh about 12,000,000 pounds; average fire apparatus weigh about 20,000 pounds. The train is some 600 times heavier. In a collision, the fire apparatus loses!

Emergencies add urgency to decision making — going through crossing warnings may create a second emergency, distract fellow responders, and cost your life.

\section{IMPORTANT SAFETY INFORMATION FROM NIOSH PLEASE READ!}

Department of Health \& Human Services

Centers for Disease Control \& Prevention

National Institute for Occupational Safety \& Health

4676 Columbia Parkway

Cincinnati, OH 45226-1998

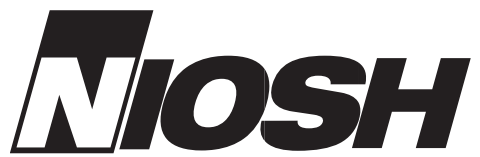

Delivering on the Nation's Promise:

Safety and health at work for all people through research and prevention 